\title{
Dengue Fever among Rural Population
}

\author{
B. Lavanya ${ }^{1}$, Mary Sophiya ${ }^{2}$, Fabiola M. Dhanaraj ${ }^{3}$ \\ ${ }^{1}$ Clinical Instructor, ${ }^{2}$ Associate Prof., ${ }^{3}$ Principal, Arulmigu Meenakshi College of Nursing, \\ Meenakshi Academy of Higher Education and Research Institute, India
}

\begin{abstract}
Background: Dengue fever is a viral illness commonly caused by Flavivirus. Dengue becomes the most common public health issues in India because the incidence of dengue fever is high all over the world. In Tamil Nadu, the existence of all the four serotypes of the dengue virus was proved during the several outbreaks of dengue fever earlier and the reported seasonal changes especially Rainfall influencing the several crucial issues of people.

Objectives: Assess the knowledge regarding dengue fever, and associate the level of knowledge with selected demographic variables.

Method: A quantitative approach and a descriptive research design for 100 samples by non-probability convenient sampling technique were used. Results: The results revealed that $10.0 \%$ of people were with inadequate knowledge of dengue fever, $58.0 \%$ of people have moderately adequate knowledge, and $32.0 \%$ of people had adequate knowledge.
\end{abstract}

Conclusion: Only a moderate level of people has adequate knowledge about dengue fever and seeks prevention.

Keywords: Assess, Knowledge, Dengue Fever, Rural Population.

\section{Introduction}

Dengue is caused by a flavivirus, It can be affected by the infected mosquito bites of anyone. Dengue is spread by a female mosquito is called Aedes aegypti which bites during the early morning and evening before dusk. It is more common in wet and warm areas.

Dengue cases increase during the beginning of the rainy season, the common symptoms of dengue is high fever, headache, joint pain, muscle pain, vomiting, and rash, most people with dengue recover within two weeks or sometimes progresses into dengue hemorrhagic

\section{Corresponding Author:}

\section{B. Lavanya}

Clinical Instructor, Arulmigu Meenakshi College of

Nursing, Meenakshi Academy of Higher Education and Research Institute, Chennai, India

e-mail: lavanyababu07@gmail.com fever. Dengue is the most life-threatening condition in the pediatric population and is highly susceptible to complications and deterioration. The fever can occur rapidly and the ability to recognize early warning signs is crucial. Approximately, 50- 100 million people are affected by dengue worldwide annually, 1000 - 20000 people died annually because of dengue. ${ }^{[6,7]}$

Dengue hemorrhagic fever it's a serious condition that will cause severe bleeding and a person will be going into the stage of Hypovolemic shock. Commonly infants, pregnant women, and older adults are at risk of developing Dengue hemorrhagic fever ${ }^{[1]}$.

Nevertheless, health is a fundamental human right of all mankind. All over the world, health care settings are striving to expand their health care service to overcome the continuous threat from the emergence and resurgence of vector burn disease ${ }^{[2]}$.

In America, 1, 346,991 dengue cases have been reported between the year January 2019 to March 
2020 and 1,530 peoples died in the same year. In India, 69,393 cases were reported in the year 2019 - 2020, and 124 deaths. Finally, in TamilNadu, 2,951 patients who had dengue fever have been treated. From this year beginning the number of dengue cases was reported in the highest numbers in Chennai, 3,034 people in Tamil Nadu has been tested positive for dengue of which the highest incidence of 543 cases was reported by Chennai till October 8“", 2019. ${ }^{[3,4]}$

Among the vector-borne disease, dengue is the major public issue in TamilNadu because nowadays cases are slightly increasing. Health care workers are also feeling difficulty in finding the cases during this COVID 19 crisis with symptoms as the cases areoverlapping and there is a high risk of the wrong diagnosis. The main aim of the study is to assess the knowledge regarding dengue fever among rural people and their ability $\mathrm{y}$ in recognizing life-threatening signs and symptoms of dengue ${ }^{[5]}$.

\section{Methodology}

The quantitative approach was adopted for the study. A descriptive research design was adopted for the study; The study Was conducted at Villapakkam among the rural population with 100 samples who fulfilled the inclusion criteria. The study adopted a convenient sampling technique. The demographic variable and modified self-structured tool were used to collect the data for the study. Getting permission and informed consent was obtained. Data were collected, organized, analyzed, and tabulated by descriptive and inferential statistics.

\section{Results}

The study findings show that the percentage of the knowledge level of dengue fever among $10^{\circ} \mathrm{c}$ of people was inadequate knowledge, $5 \mathrm{~S} .0 \%$ were the moderately adequate level of knowledge and $32 \%$ of them were having an adequate level of knowledge about dengue fever.

Table 1: Frequency distribution of level of knowledge of dengue fever at Villapakkam village $\mathrm{n}=\mathbf{1 0 0}$

\begin{tabular}{|l|c|c|}
\hline Level of knowledge & Frequency & Percentage \\
\hline Inadequate knowledge & 10 & $10.0 \%$ \\
\hline Moderately Adequate knowledge & 58 & $58.0 \%$ \\
\hline Adequate knowledge & 32 & $32.0 \%$ \\
\hline
\end{tabular}

The percentage of the mean score of the knowledge of dengue fever at Villapakkam village in the study group.

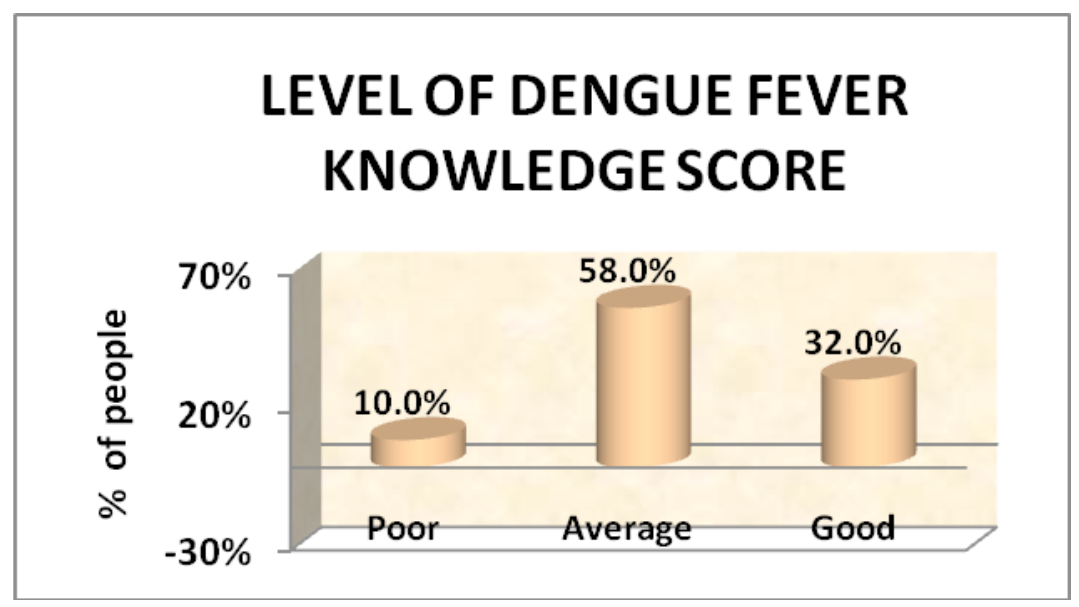

Fig. 1: Frequency percentage of level of knowledge of dengue fever at Villapakkam village

The analysis depicted that rural people are having more knowledge scores regarding dengue fever $(95.0 \%)$ and a minimum score of $11.0 \%$ regarding the drugs used to avoid dengue fever. In the association between the level of knowledge score and people with demographic variables, younger males are more knowledgeable scores than the other groups which were statistically significant calculated using the chi-square test. ( $\mathrm{P}=41 . \mathrm{Of})$. 


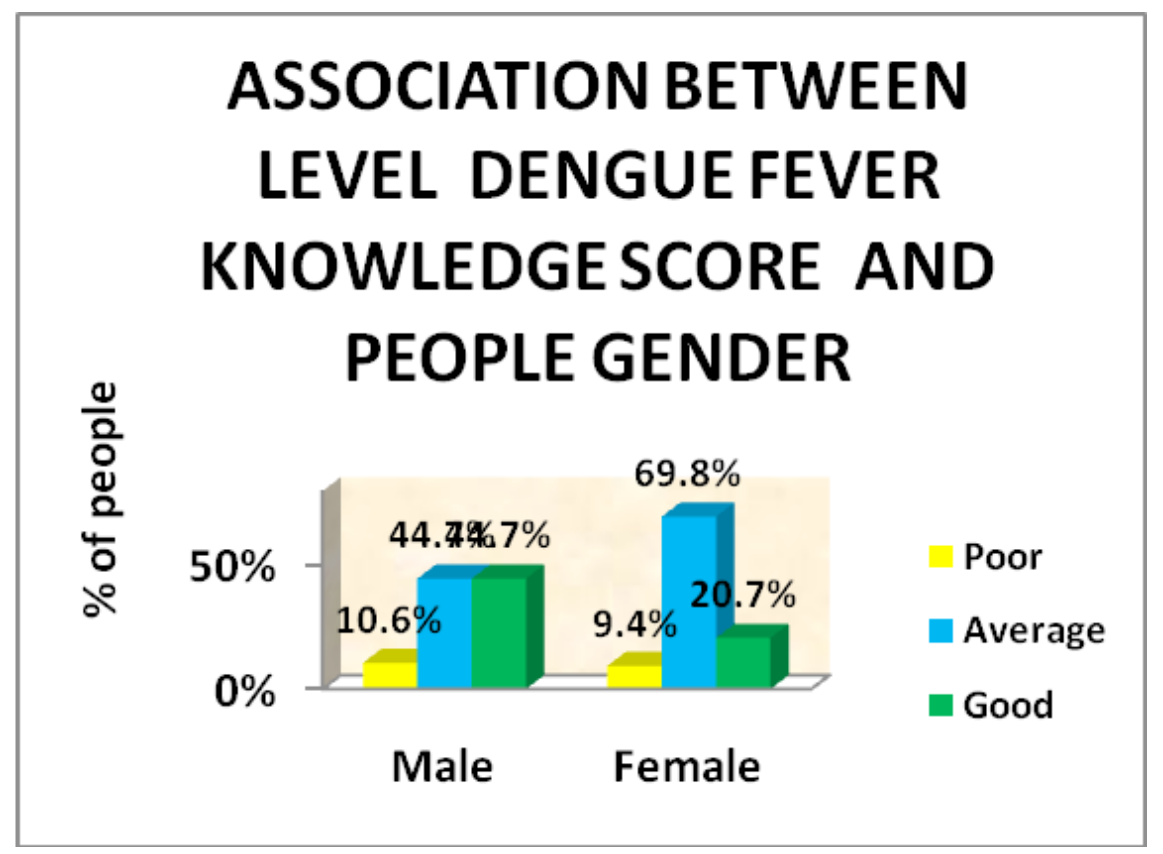

Fig 2: Association between the level of knowledge of dengue fever score in gender in the Villapakkam village people

Table 2: Association between the level of knowledge and the demographic variables. $n=100$

\begin{tabular}{|c|c|c|c|c|c|c|c|c|c|}
\hline \multirow{3}{*}{\multicolumn{2}{|c|}{ Demographic variables }} & \multicolumn{6}{|c|}{ Level of knowledge } & \multirow{3}{*}{ Total } & \multirow{3}{*}{ Chi square test } \\
\hline & & \multicolumn{2}{|c|}{ Poor } & \multicolumn{2}{|c|}{ Average } & \multicolumn{2}{|c|}{ Good } & & \\
\hline & & $\mathbf{n}$ & $\%$ & $\mathbf{n}$ & $\%$ & $\mathbf{n}$ & $\%$ & & \\
\hline \multirow{4}{*}{ Age } & 20-30 years & 0 & $0.0 \%$ & 20 & $54.1 \%$ & 17 & $45.9 \%$ & 37 & \multirow{4}{*}{$\begin{array}{c}\chi 2=16.44 \mathrm{P}=0.01 * * \\
\mathrm{DF}=6 \text { significant }\end{array}$} \\
\hline & $31-40$ years & 2 & $8.3 \%$ & 14 & $58.3 \%$ & 8 & $33.4 \%$ & 24 & \\
\hline & $41-60$ years & 3 & $13.0 \%$ & 15 & $65.2 \%$ & 5 & $21.7 \%$ & 23 & \\
\hline & $>60$ years & 5 & $31.2 \%$ & 9 & $56.3 \%$ & 2 & $12.5 \%$ & 16 & \\
\hline \multirow{2}{*}{ Gender } & Male & 5 & $10.6 \%$ & 21 & $44.7 \%$ & 21 & $44.7 \%$ & 47 & \multirow{2}{*}{$\begin{array}{l}\chi 2=7.20 \mathrm{P}=0.05^{*} \\
\mathrm{DF}=2 \text { significant }\end{array}$} \\
\hline & Female & 5 & $9.4 \%$ & 37 & $69.8 \%$ & 11 & $20.7 \%$ & 53 & \\
\hline \multirow{4}{*}{$\begin{array}{l}\text { Educational } \\
\text { status }\end{array}$} & Elementary school & 5 & $18.5 \%$ & 18 & $66.6 \%$ & 4 & $14.8 \%$ & 27 & \multirow{4}{*}{$\begin{array}{c}\chi 2=12.90 \mathrm{P}=0.05^{* *} \\
\mathrm{DF}=6 \text { significant }\end{array}$} \\
\hline & High school & 4 & $11.8 \%$ & 21 & $61.8 \%$ & 9 & $26.5 \%$ & 34 & \\
\hline & Higher secondary & 1 & $4.2 \%$ & 13 & $54.2 \%$ & 10 & $41.7 \%$ & 24 & \\
\hline & Degree holder & 0 & $0.0 \%$ & 6 & $40.0 \%$ & 9 & $60.0 \%$ & 15 & \\
\hline \multirow{2}{*}{ Type of family } & Joint family & 3 & $5.5 \%$ & 31 & $56.4 \%$ & 23 & $41.8 \%$ & 55 & \multirow{2}{*}{$\begin{array}{l}\chi 2=6.46 \mathrm{P}=0.05^{*} \\
\mathrm{DF}=2 \text { significant }\end{array}$} \\
\hline & Nuclear family & 7 & $15.6 \%$ & 29 & $64.4 \%$ & 9 & $20.0 \%$ & 45 & \\
\hline
\end{tabular}

Further, in the association between the level of knowledge score and educational status, it is found that $26.5 * / \mathrm{c}$ of the rural people with high school education have good knowledge, and $64.4 \%$ of the rural people hailing from nuclear family has average knowledge regarding dengue fever which was statistically significant. $(\mathrm{P}=0.05)$.

\section{Discussion}

Based on the objectives of the research, the dengue fever knowledge among the rural populations in the community is discussed objective wise. The first objective was to assess the knowledge regarding dengue fever, the result revealed that their knowledge score about dengue fever is good (95.5\%) and the minimum 
score regarding avoidance of drugs during dengue fever (1 I .0\%). The second objective was to associate the level of knowledge with selected demographic variables, reveals the association between the level of knowledge score and the demographic variables. The younger age groups are having more knowledge (45.9\%) and joint family people are having more knowledge scores (41.\%) than others, whereas, $64.4 \%$ of the rural people hailing from nuclear families have average knowledge regarding dengue fever which was statistically significant. Age group more than 60 are having poor knowledge. Dengue is a major health burden in India. Annually the number of dengue cases is increasing.

The Government has taken some steps to overcome the COVID 19 crisis. The seasonal epidemic of dengue is started now in Chennai and in some of the areas, there are complaints of the mosquito menace escalating. Therefore, the city corporation has transferred all domestic breeding checkers from COVID 19 duty to vector control work and conducting the fever camps. The government also is creating awareness and taking steps to control breeding. The health care professionals also playing a vital role in taking some precautionary measures to control the spread of dengue making sure that water stagnation is not allowed anywhere.

Emmanuelle Kumaran (2018) conducted a study to assess the knowledge, attitude, and behavior of dengue fever among the rural people in the selected community area the study revealed that the knowledge on dengue fever symptoms, transmission, and prevention method was high. (96.7\%) of people were able to identify mosquitoes as being the dengue vector. Most of the people were able to identify the biting time of dengue mosquito's, although, $17.8 \%$ of participants were having knowledge on dengue causing mosquitoes to bite the person at night time. (95.5\%) of peoples were have adequate knowledge about least breeding sites of dengue mosquito.

\section{Conclusion}

Dengue fever is a disease that can take a toll on people if they are not educated. This study has proved that rural people need to be educated to prevent dengue.
Serious steps have to be taken by the Government on taking preventive measures programs in the rural areas as the major it $y$ of the population of India is in the rural areas.

Acknowledgments: I would like to express my sincere thanks to Panchayat Officer, Villapakkam Village for Granting permission and arranging the facilities to carry out this research. 1 would also like to extend my heartfelt thanks to our samples for their active participation and cooperation in data collection.

\section{Ethical Clearance: Nil}

Source of Funding: Meenakshi Academy of Higher Education and Research, Chennai, India.

\section{Conflict of Interest: Nil}

\section{References}

1. Park K. Preventive and social medicine.

2. Ahmad R, Suzilah I, Wan Najdah WM, Topek O, Mustafakamal I, Lee HL. Factors determining dengue outbreak in Malaysia. PloS one. 2018 Feb 23;13(2):e0193326.

3. Nalongsack S, Yoshida Y, Morita S, Sosouphanh K, Sakamoto J. Knowledge, attitude and practice regarding dengue among people in Pakse, Laos. Nagoya J Med Sci. 2009 Feb 1;71(1-2):29-37.

4. Taksande A, Lakhkar B. Knowledge, attitude and practice (KAP) of dengue fever in the rural area of central India. Shiraz E-Med J. 2012 Oct;13(4):14657.

5. Wilder-Smith A, Ooi EE, Horstick O, Wills B. Dengue. The Lancet. 2019 Jan 26;393(10169):35063.

6. World Health Organization, Special Programme for Research, Training in Tropical Diseases, World Health Organization. Department of Control of Neglected Tropical Diseases, World Health Organization. Epidemic, Pandemic Alert. Dengue: guidelines for diagnosis, treatment, prevention and control. World Health Organization; 2009.

7. World Health Organization (WHO), Dengue Situation 